\title{
Prevalence of bullying victimisation among primary school children in South Africa: a population-based study
}

\author{
Donnay Manuel ${ }^{1^{*}}\left(\mathbb{D}\right.$, Sabirah Adams ${ }^{2}$, Mulalo Mpilo ${ }^{1}$ and Shazly Savahl ${ }^{1}$
}

\begin{abstract}
Objectives: Bullying victimisation (BV) among children in South Africa has been identified as a major public health concern. While several studies report on the prevalence rates of $\mathrm{BV}$, there is currently a dearth of research that reports on the prevalence of $B V$ among a national sample of primary school children. This study determines the prevalence rates of BV among a nationally representative sample of school-going children in South Africa across provinces, age, and gender. The sample comprised 7067 children (boys = 45.6\%; girls $=54.4 \%$ ) between the ages of 10-12-years attending 61 primary schools across the nine provincial regions of South Africa.

Results: In terms of 'being hit' by other children, percentages range from 22.55\% (North West) to 33.34\% (Free State). Children in Gauteng (33.59\%) and Limpopo (38.54\%) had the highest percentage of children being 'left out' or excluded. Additionally, across all provinces more than $30 \%$ of children reported that they had been 'called unkind names.' Across gender, boys are more likely to experience all three forms of BV (being hit, left out, and called unkind names). The findings further indicate that 10-year-olds reported being 'hit' and 'left out', whereas a greater percentage of 12-year-olds reported 'being called unkind names' (44.28\%).
\end{abstract}

Keywords: Bullying victimisation, Children, Prevalence, South Africa

\section{Introduction}

Bullying victimisation (BV) among school children is an international public health concern [1]. It can be understood as a subset of aggressive behaviour [2], or a form of interpersonal aggression [3, 4]. Olweus [5], a pioneer of bullying research, defines bullying as intentionally and repeatedly inflicting harm on an individual, with a power imbalance between the perpetrator and victim. Although there is contestation concerning how bullying is defined, there is a degree of consensus among researchers that in order for bullying to occur there has to be intent, repetitiveness, and a power imbalance [2].

\footnotetext{
*Correspondence: 3165160@myuwc.ac.za

${ }^{1}$ Centre for Interdisciplinary Studies of Children, Families and Society,

University of the Western Cape, Cape Town, South Africa

Full list of author information is available at the end of the article
}

The different forms of bullying have been categorised into two distinct groups, namely direct (including hitting and name-calling) and indirect (including spreading rumours and social exclusion) bullying [6-9]. Research has shown that boys are more likely to engage in direct forms of bullying, whereas girls are more likely to engage in indirect forms of bullying [10-12]. Although the incidence of BV generally decreases with age, some research studies have found an increase in bullying perpetration with age $[13,14]$ Additionally, there appears to be a shift in the forms of bullying children experience as they age, from direct to indirect forms of bullying $[15,16]$.

These different conceptualisations and forms of bullying have implications for developing appropriate intervention and policy responses. In particular, it influences the reporting of prevalence rates within and across different contexts. The rate of $\mathrm{BV}$ among children is a

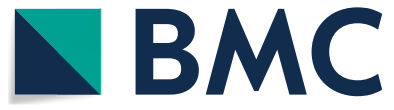

(c) The Author(s) 2021. Open Access This article is licensed under a Creative Commons Attribution 4.0 International License, which permits use, sharing, adaptation, distribution and reproduction in any medium or format, as long as you give appropriate credit to the original author(s) and the source, provide a link to the Creative Commons licence, and indicate if changes were made. The images or other third party material in this article are included in the article's Creative Commons licence, unless indicated otherwise in a credit line to the material. If material is not included in the article's Creative Commons licence and your intended use is not permitted by statutory regulation or exceeds the permitted use, you will need to obtain permission directly from the copyright holder. To view a copy of this licence, visit http://creativecommons.org/licenses/by/4.0/. The Creative Commons Public Domain Dedication waiver (http://creativeco mmons.org/publicdomain/zero/1.0/) applies to the data made available in this article, unless otherwise stated in a credit line to the data. 
key indicator of children's well-being, and an important marker for comparing global social development [17]. Several international studies have reported on the prevalence rates of school-based bullying across various socio-economic contexts. These include the Health Behaviour in School-aged Children (HBSC) conducted across 43 high-income countries in Europe and North America, the Global School-based Student Health Survey (GSHS) conducted across over 90 low- and middleincome countries, the Program for International Student Assessment (PISA), the Progress in International Reading Study (PIRLS), and the Children's Worlds Survey. The prevalence rates in these studies range from 9 to $44.5 \%$ $[9,17-23]$.

A recent international comparative study found that South Africa had the highest prevalence of school-based BV across 15 countries [9]. While earlier studies report prevalence rates between 13 and 43\% [22, 24-26], there is currently no study that provides prevalence rates on BV among primary school children using a national representative sample across age groups. The current study addresses this gap in the literature. We use data from Wave 3 of the South Africa Children's Worlds Study to report on the prevalence rates of BV using a national population-based sample. More specifically, we report on the prevalence of three forms of BV across the nine provinces, gender, and across two age groups (10 and 12). Finally, we also report on the likelihood of children experiencing different forms of BV by province, gender, and age.

\section{Main text \\ Method \\ Research design and sampling}

The study uses secondary data from Wave 3 of the South Africa Children's Worlds: International Survey on Children's Well-Being (see www.isciweb.org). The survey was conducted across 35 countries, and is the largest multinational study assessing children's subjective perceptions of their well-being across different contexts and domains [27]. In South Africa, we used a school-based sample comprising a nationally representative proportionate sample of children aged 10- and 12-years old. In South Africa, children in these two age groups are generally in grades 4 and 6 . We used stratified random sampling (proportional allocation), with schools selected proportionate to the number of learners per province for each age group, and stratified further in terms of urban and rural geographical locations. The final dataset consisted of 7067 participants $($ boys $=45.6 \%$; girls $=54.4 \%$ ) between the ages of 9 and 12-years $\left(M_{\text {age }}=10.79 ; S D=1.28\right)$, in Grades $4(\mathrm{n}=3383)$ and $6(\mathrm{n}=3684)$, attending 61 primary schools across the nine provincial regions of South Africa.

\section{Instrumentation}

We translated the questionnaire into seven official South African languages using the International Test Commission's Guidelines for Adapting and Translating Tests [28]. This process comprised the backwardtranslation method, the review of an expert panel, and cognitive testing with participants with similar characteristics to the target population. The Children's Worlds Survey included three items on BV, assessing direct and indirect bullying. These items are as follows:

i. How often in the last month have you been hit by other children in your school?

ii. How often in the last month have you been left out by other children in your school?

iii. How often in the last month have you been called unkind names by other children in your school?

These items were scored on a 4-point frequency scale using the following response options: 0 (never); 1 (once); 2 ( 2 or 3 times); and 3 (more than 3 times). In the current study, we merged the last two categories ('2 or 3 times' and 'more than 3 times') into a category called ' 2 or more times' for ease of interpretation.

\section{Data analysis}

Data were analysed using Stata 14. The final dataset was weighted based on the proportion of children per province. Weighting is employed with population-level data in order to adjust the sample to be more representative of the target population [29], and to ensure accurate standard errors and parameter estimates [30]. In this descriptive article, we report on the prevalence and frequencies of different forms of BV across age, gender, and the nine provincial regions in South Africa. We also report on the likelihood ratio of experiencing the three forms of BV across the aforementioned groups. We calculated the likelihood ratio by dividing the larger percentage, experiencing $\mathrm{BV}$, with the corresponding smaller percentage of the two groups being compared (age and gender). The ratio represents the likelihood of groups experiencing a type of BV, whereby a larger ratio reflects a greater likelihood/disparity across groups [31].

\section{Procedure and ethics}

We obtained ethics clearance from the Institutional Review Board of the University of the Western Cape. We 
Frequency of being hit, left out, and called unkind names by other children 2 or more times across 9 Provinces

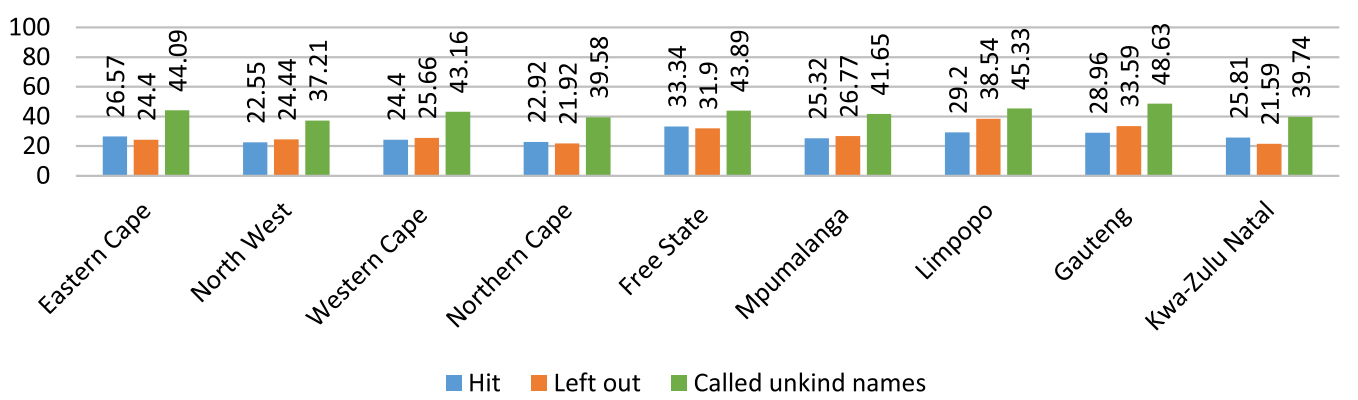

Fig. 1 Frequency of being hit, left out, and called unkind names by other children ' 2 or more times' across nine Provinces

Frequency of being hit, left out, and called unkind names by other children more than 2 times in South Africa

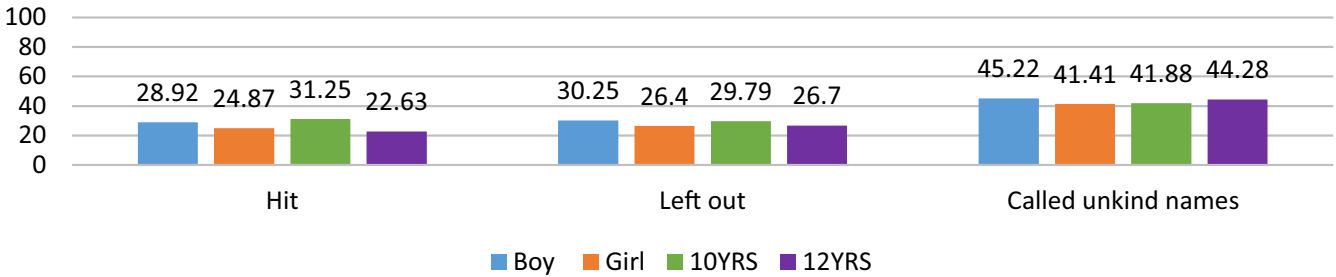

Fig. 2 Overall frequency of being hit, left out, and called unkind names by other children '2 or more times' across gender and age

obtained consent from both the participants and their parent/guardian. Data collection followed a researcheradministered protocol wherein the research team administered the questionnaire to the participants by reading each question and explaining the response options.

\section{Results}

The aim of the study was to determine the prevalence rates of BV among primary school children in South Africa across the nine provinces, age, and gender. We present the frequency of the three BV items across the nine provinces in Fig. 1. We found considerable differences for the different forms of bullying across the provinces. The highest prevalence across all provinces was for being 'called unkind names', with the highest prevalence rate in Gauteng (48.63\%) and the lowest in North West (37.21\%). For those reporting 'being hit' two or more times, the prevalence ranged from $22.55 \%$ in the North West to $33.34 \%$ in the Free State. Gauteng (33.59\%) and Limpopo (38.54\%) had the highest prevalence of children feeling 'left out' (excluded) '2-or-more times' in the last month.

Figure 2 presents the overall frequency of the different forms of BV across gender and age. Boys reported higher prevalence rates across all three forms of BV. A higher proportion of boys reported being hit (28.92\%), 'left out' (30.25\%), and 'called unkind names' (45.22\%). We also found that a higher percentage of 10-year-olds reported 'being hit' (31.25\%) and 'left out' (29.79\%), while a higher percentage of 12-year-olds reported being 'called unkind names' (44.28\%).

Finally, we present the likelihood ratios of experiencing bullying victimisation across province, age, and gender in Table 1. There were substantial differences in the likelihood ratio among children who experienced different forms of BV across age and gender.

We found that 10-year-olds were more likely to be 'hit' by other children across all provinces, with the largest group difference in the North West (2.51 times more likely) and the smallest in the Northern Cape (1.04 times more likely). There were similar patterns for being 'left out' by other children, with 10 -year olds more likely to experience being 'left out' in most provinces, with the exception of the Eastern Cape and Kwa-Zulu Natal. We found the largest group difference in the Western Cape with 10-year-olds being 1.51 times more likely to be 'left out' than 12-year-olds. However, age differences for being 'called unkind names' were less pronounced. In five 
Table 1 Likelihood ratio of being bullied across age and gender within the nine provinces

\begin{tabular}{|l|l|}
\hline 10 -year olds $>12$-year olds & Boys $>$ Girls \\
\hline 12 -year olds $>10$-year olds & Girls $>$ Boys \\
\hline
\end{tabular}

\begin{tabular}{|c|c|c|c|c|c|c|}
\hline & \multicolumn{3}{|c|}{ Age group ratios } & \multicolumn{3}{|c|}{ Gender ratios } \\
\hline & Hit & Excluded & $\begin{array}{c}\text { Called unkind } \\
\text { names }\end{array}$ & Hit & Excluded & $\begin{array}{c}\text { Called unkind } \\
\text { names }\end{array}$ \\
\hline Eastern Cape & 1.24 & 1.39 & 1.52 & 1.16 & 1.16 & 1.05 \\
\hline North West & 2.51 & 1.08 & 1.25 & 1.26 & 1.03 & 1.04 \\
\hline Western Cape & 1.51 & 1.51 & 1.13 & 1.45 & 1.02 & 1.07 \\
\hline Northern Cape & 1.04 & 1.05 & 1.75 & 1.60 & 1.01 & 1.29 \\
\hline Free State & 2.12 & 1.41 & 1.27 & 1.10 & 1.53 & 1.22 \\
\hline Mpumalanga & 1.93 & 1.14 & 1.06 & 1.26 & 1.12 & 1.30 \\
\hline Limpopo & 1.24 & 1.35 & 1.13 & 1.03 & 1.15 & 1.01 \\
\hline Gauteng & 1.39 & 1.16 & 1.04 & 1.20 & 1.10 & 1.05 \\
\hline Kwa-Zulu Natal & 1.20 & 1.12 & 1.35 & 1.06 & 1.23 & 1.15 \\
\hline
\end{tabular}

provinces (North West, Western Cape, Northern Cape, Free Sate, and Kwa-Zulu Natal), 12-year-olds were more likely to be 'called unkind names', with the largest difference in the Northern Cape (1.75). On the other hand, in four provinces (Eastern Cape, Mpumalanga, Limpopo, and Gauteng), 10-year-olds were more likely to experience this form of BV (Additional file 1: Table S1).

In terms of gender, boys were more likely than girls to be 'hit' in seven provinces; the largest difference was in the Northern Cape with boys 1.60 times more likely than girls to experience this form of bullying. However, in Limpopo (1.03) and Gauteng (1.20), girls were more likely to be 'hit' than boys. Similarly, boys were more likely to be 'left out' than girls in seven provinces. However, in two provinces (Western and Northern Cape) girls were more likely to be 'left out' than boys. Finally, boys were more likely to experience being 'called unkind names' in all the provinces, with the greatest gender difference in $\mathrm{Mpu}$ malanga (1.30 times more likely), and the smallest (1.04) gender difference in the North West.

\section{Discussion}

The aim of the study was to determine the prevalence rates of three forms of BV among primary school children in South Africa across the nine provinces, across age and gender. Across all provinces, the highest prevalence was for being 'called unkind names. This finding aligns to those found in most countries that participated in previous waves of the Children's Worlds Survey [31]. We found a higher prevalence of BV in the Free State, Limpopo, and Gauteng. There are no obvious reasons explaining this trend, given the diverse geographical (urban and rural) and socio-economic contexts of these provinces. While the Free State and Limpopo provinces have a larger rural population and lower levels of economic productivity, the Gauteng province is largely urban and is the most economically productive province in the country. The prevalence rates were higher for boys than girls across all three forms of BV. This finding aligns to previous cross-cultural research conducted by Savahl et al. [9] and Smith et al. [32]. Younger children experienced being 'hit' and 'left out' more, while older children were more likely to experience being 'called unkind names'. This trend is likely as a result of childhood developmental patterns [31, 33].

A trend identified in the empirical literature of boys being more likely to engage in physical forms of bullying and girls more likely to engage in indirect forms of bullying $[12,18]$ was not found in the current study. Rather, we found that boys were more likely to experience all forms of bullying across most of the provinces. However, while the prevalence was higher for boys than girls, the prevalence rates for girls were similarly high across the three forms of bullying. Consistent with the literature, we found that 'being hit' and 'left out' decreased with age (see [14, 34]); however, there was no decrease for being 
'called unkind names'. This relational form of bullying appears to have a different trajectory to other forms of bullying and confirms Savahl et al's [9] contention that bullying is not a homogenous experience and that there are diverse dynamics across the different forms. Across age, forms of BV also appeared to shift from a physical (being hit) to a verbal form (called unkind names), which is aligned to reported shifts from direct to indirect forms of bullying as children get older $[15,16]$.

\section{Limitations}

We asked respondents to report on their experiences of three forms of BV over the past month. This restriction may not necessarily capture longer periods of victimisation. The aim of the current study was merely to establish the degree to which children in South Africa experience BV and does not highlight the correlates or predictors of BV. Future studies should therefore focus on the contextual factors associated with BV among children in South Africa.

\begin{abstract}
Abbreviations
BV: Bullying victimisation; HBSC: Health Behaviour in School-aged Children; GSHS: Global School-based Student Health Survey; PISA: Program for International Student Assessment; UNESCO: United Nations Educational, Scientific and Cultural Organization; PIRLS: Progress in International Reading Study.
\end{abstract}

\section{Supplementary Information}

The online version contains supplementary material available at https://doi. org/10.1186/s13104-021-05747-w.

Additional file 1: Table S1. Proportion of children per province.

\section{Acknowledgements}

Not applicable.

\section{Authors' contributions}

DM, SS and SA conceptualised and designed the study. SS and SA are the principal investigators of the larger study. DM wrote the introduction, rationale and method with SA and SS. DM and MP conducted the analysis and reported on the results. DM, SS and SA wrote the discussion. DM wrote the conclusion and limitations. All authors read and approved the final manuscript.

\section{Funding}

This project was supported by the Jacobs Foundation and the National Research Foundation of South Africa.

\section{Availability of data and materials}

The data that support the findings of this study are available from the International Society for Child Indicators, but restrictions apply to the availability of these data, which were used under license for the current study, and so are not publicly available. Data are however available from the authors upon reasonable request and with permission of the International Society for Child Indicators.

\section{Declarations}

\section{Ethics approval and consent to participate}

The South Africa Children's Worlds study obtained ethics clearance from the Humanities and Social Sciences Research Ethics Committee of the University of the Western Cape, and the nine provincial education departments. Child participants were informed of the rationale of the study, its subsequent aims and objectives, and what the nature of their anticipated role within the research study. Written informed consent was required from both children and their parents, in a language that they understand, as per the university and legal requirements. Children were given sufficient time to consider the information of the study, reflect on their decision to participate, and have any questions answered before providing their consent. Participants were informed to their right to non-participation without discrimination, which was applicable at any time or phase of the study.

\section{Consent for publication}

Not applicable.

\section{Competing interests}

The authors declare that they have no competing interests.

\section{Author details}

${ }^{1}$ Centre for Interdisciplinary Studies of Children, Families and Society, University of the Western Cape, Cape Town, South Africa. ${ }^{2}$ Language Development Group, Centre for Higher Education Development, University of Cape Town, Cape Town, South Africa.

Received: 19 April 2021 Accepted: 18 August 2021

Published online: 30 August 2021

\section{References}

1. UNESCO. School violence and bullying: global status report. United Nations. 2017.

2. Smith PK, Cowie H, Olafsson RF, Liefooghe AP. Definitions of bullying: a comparison of terms used, and age and gender differences, in a fourteen-country international comparison. Child Dev. 2002;73(4):1119-33. https://doi.org/10.1111/1467-8624.00461.

3. Vaillancourt T, Hymel S, McDougal P. Bullying is power: implications for school-based intervention strategies. J Appl Psychol. 2003;19(2):157-76. https://doi.org/10.1300/J008v19n02_10.

4. Koo H. A time line of the evolution of school bullying in differing social contexts. Asia Pac Educ Rev. 2007;8:107-16. https://doi.org/10.1007/ BF03025837.

5. Olweus D. Aggression in the schools: bullies and whipping boys. London: Hemisphere Press; 1978.

6. Navarro R, Ruiz-Oliva R, Larra naga, E., \& Yubero, S. The impact of cyberbullying and social bullying on optimism, global and school-related happiness and life satisfaction among 10-12-year-old school children. Appl Res Qual Life. 2015;10:15-36. https://doi.org/10.1007/s11482-013-9292-0.

7. Olweus D. School bullying: development and some important challenges. Annu Rev Clin Psychol. 2013;9:751-80. https://doi.org/10.1146/ annurev-clinpsy-050212-185516.

8. Van der Wal MF, De Wit CA, Hirasing RA. Psychosocial health among young victims and offenders of direct and indirect bullying. Pediatrics. 2003;111(6):1312-7

9. Savahl S, Montserrat C, Casas F, Adams S, Tiliouine H, Benninger E, Jackson $K$. Children's experiences of bullying victimization and the influence on their subjective well-being: a multinational comparison. Child Dev. 2019;90(2):414-31. https://doi.org/10.1111/cdev.13135.

10. Boyes ME, Bowes $L$, Cluver LD, Ward CL, Badcock NA. Bullying victimization, internalising symptoms, and conduct problems in South African children and adolescents: a longitudinal investigation. J Abnorm Child Psychol. 2014;42(8):1313-24. https://doi.org/10.1007/s10802-014-9888-3.

11. Craig W, Harel-Fisch Y, Fogel-Grinvald H, Dostaler S, Hetland J, SimonsMorton B, Malcho M, de Mato MG, Overpeck M, Due P, Pickett W. A cross-national profile of bullying and victimization among adolescents in 40 countries. Int J Public Health. 2009:54(2):216-24. 
12. Tiliouine $\mathrm{H}$. School bullying victimization and subjective well-being in Algeria. Child Indic Res. 2015;8:133-50. https://doi.org/10.1007/ s12187-014-9286-y.

13. Due P, Merlo J, Harel-Fisch Y, Damsgaard MT, Holstein BE, Hetland J, Currie C, Gabhainn SN, de Matos Mg, Lynch J. Socioeconomic inequality in exposure to bullying during adolescence: a comparative, cross-sectional, multilevel study in 35 countries. Am J Public Health. 2009;99(5):907-14.

14. World Health Organization-WHO. Social determinants of health and well-being among young people. Health behaviour in school-aged children (HBSC) study: international report from the 2009/2010 survey. 2012. http://www.euro.who.int/_data/assets/pdf_file/0007/167425/E96444_ part2_5.pdf. Accessed 14 Feb 2020.

15. Cross D, Lester L, Barnes A. A longitudinal study of the social and emotional predictors and consequences of cyber and traditional bullying victimization. Int J Public Health. 2015;60(2):207-17. https://doi.org/10. 1007/s00038-015-0655-1.

16. Monks CP, Smith PK, Naylor P, Barter C, Ireland JL, Coyne I. Bullying in different contexts: commonalities, differences and the role of theory. Aggress Violent Beh. 2009;14(2):146-56. https://doi.org/10.1016/j.avb. 2009.01.004.

17. Richardson D, Hiu CH. Developing a global indicator on bullying of school aged children. Florence: UNICEF Office of Research-Innocenti Working Paper; 2018.

18. UNESCO. Behind the numbers: ending school violence and bullying. United Nations. 2019.

19. Brown DW, Riley L, Butchart A, Kann L. Bullying among youth from eight African countries and associations with adverse health behaviors. Pediatr Health. 2008;2(3):289-99. https://doi.org/10.2217/17455111.2.3.289.

20. Hazemba A, Siziya S, Muula AS, Rudatsikira E. Prevalence and correlates of being bullied among in-school adolescents in Beijing: results from the 2003 Beijing Global School-Based Health Survey. Ann Gen Psychiatry. 2008;7(1):6. https://doi.org/10.1186/1744-859X-7-6.

21. Kubwalo HW, Muula AS, Siziya S, Pasupulati S, Rudatsikira E. Prevalence and correlates of being bullied among in-school adolescents in Malawi: results from the 2009 Global School-Based Health Survey. Malawi Med J. 2013;25(1):12-4. https://doi.org/10.1186/1744-859X-7-6.

22. Howie SJ, Combrinck C, Roux K, Tshele M, Mokoena GM, Palane NM. Progress in International Reading Literacy Study (PIRLS) 2016: South African children's reading literacy achievement. Pretoria: centre for evaluation and assessment. 2017

23. OECD. Programme for international student assessment (PISA) 2018 results: what school life means for students'lives, vol. III. Paris: OECD Publishing; 2019. https://doi.org/10.1787/acd78851-en.
24. Liang H, Flisher AJ, Lombard CJ. Bullying, violence, and risk behavior in South African school students. Child Abuse Negl. 2007;31(2):161-71. https://doi.org/10.1016/j.chiabu.2006.08.007.

25. Mlisa LN, Ward CL, Flisher AJ, Lombard CJ. Bullying at rural high schools in the Eastern Cape Province, South Africa: Prevalence, and risk and protective factors at school and in the family. J Psychol Afr. 2008;18(2):261-7. https://doi.org/10.1080/14330237.2008.10820195.

26. Thomas HJ, Connor JP, Lawrence DM, Hafekost JM, Zubrick SR, Scott JG. Prevalence and correlates of bullying victimisation and perpetration in a nationally representative sample of Australian youth. Aust N Z J Psychiatry. 2017;51(9):909-20. https://doi.org/10.1177/0004867417707819.

27. Savahl S. Children's hope in South Africa: a population-based study. Front Psychol. 2020. https://doi.org/10.3389/fpsyg.2020.01023.

28. International Test Commission. The ITC guidelines for translating and adapting tests (second edition). 2017. www.InTestCom.org. Accessed 13 June 2021.

29. Kalton G, Flores-Cervantes I. Weighting methods. J Off Stat. 2003;19(2):81-97.

30. Hahs-Vaughn DL. A primer for using and understanding weights with national datasets. J Exp Educ. 2005;73(3):221-48. https://doi.org/10.3200/ JEXE.73.3.221-248.

31. Rees G, Main G. Children's views on their lives and well-being in 15 countries: an initial report on the Children's Worlds survey. 2013-14. Children's Worlds Project (ISCWeB). 2015.

32. Smith PK, López-Castro L, Robinson S, Görzig A. Consistency of gender differences in bullying in cross-cultural surveys. Aggress Violent Behav. 2019:45:33-40. https://doi.org/10.1016/j.avb.2018.04.006.

33. Borualogo IS, Casas F. Subjective well-being of bullied children in Indonesia. Appl Res Qual Life. 2021;16:753-73. https://doi.org/10.1007/ s11482-019-09778-1.

34. Pečjak S, Pirc T. Bullying and perceived school climate: victims' and bullies' perspectives. Studia Psychologica. 2017;50(1):22-33. https://doi.org/10. 21909/sp.2017.01.728.

\section{Publisher's Note}

Springer Nature remains neutral with regard to jurisdictional claims in published maps and institutional affiliations.
Ready to submit your research? Choose BMC and benefit from:

- fast, convenient online submission

- thorough peer review by experienced researchers in your field

- rapid publication on acceptance

- support for research data, including large and complex data types

- gold Open Access which fosters wider collaboration and increased citations

- maximum visibility for your research: over 100M website views per year

At $B M C$, research is always in progress.

Learn more biomedcentral.com/submissions 